\title{
Investigation of Suspension Ball Joint Pull Out Force Based on FEA Method and Experimental Study
}

\author{
${ }^{*}$ Alimurtaza RUTCI and ${ }^{2}$ F. Selman EREN \\ ${ }^{* 1}$ Teknorot Automotive Product Industry, Research-Development Center, Düzce -Turkey \\ ${ }^{2}$ Teknorot Automotive Product Industry, Research-Development Center, Düzce -Turkey
}

\begin{abstract}
Suspension ball joints are always used to connect the control arms to the knuckle since they are the only joints which allow three degrees of rotational freedom. On the purpose of a sufficient performance of the ball joint, it is very important to prevent the extraction of the ball stud from the ball joint housing. Ball joint's housing material and shape design must withstand axial loads in the ball stud from axial direction in order to avoid the ball stud pull out keeping the ball stud inside the housing. The ball stud pull out force is a critical and safety characteristic function because it is related to failure mode for front suspension system. These paper investigate how to determine of suspension ball joint pull out force based on FEA method and experimental study. With respect to results of finite element analysis and experimental study, it is possible to monitoring deformation and displacement versus the load. The result of FE analysis and design verifications make it possible to determination of suspension ball joint pull out force.
\end{abstract}

Key words: Ball joint, pull out force, fea, experimental study.

\section{Introduction}

Ball joint is the one of the main component of the suspension and steering systems of the vehicles. This component is responsible to connect two vehicle modules allowing rotation and oscillation movements in both suspension and steering systems of the vehicles. Ball joints have critical function in both systems and defined as a safety part. These components are exposed to different kind of loads during ride and it has to be sure that the component is safe enough. To obtain the strength of the component there are some tests should be done. One of the test is the pull-out of the ball stud. This study aims to accomplish this test via Finite Element Method using ANSYS and then make the correlation of the simulation results with experimental study.

Figure 1 shows an assembly of ball joint in front suspension system. Suspension system consist of control arm, control arm bushing, steering knuckle and ball joint. The purpose of a ball joint is to transfer the wheel forces to the suspension links without applying any torque.

*Corresponding author: Address: 1. Organize Sanayi Bölgesi 1. Cadde No: 5 Beyköy, Düzce / TURKEY.

E-mail address: alimurtaza.rutci@teknorot.com Phone:+908502003864 


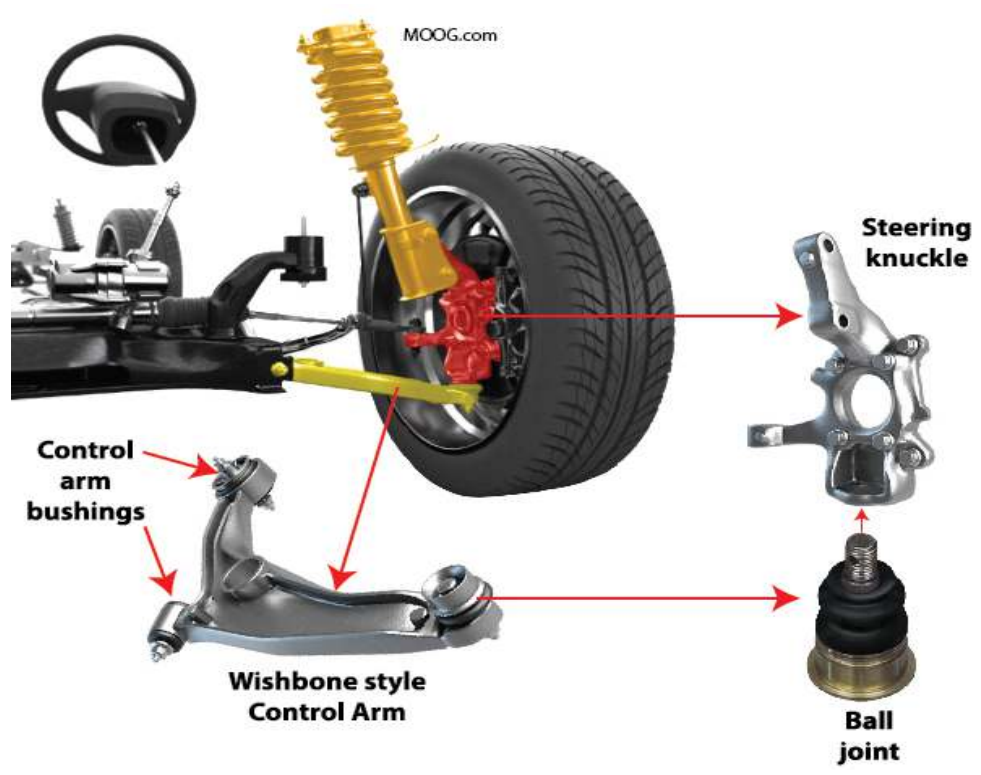

Figure 1. An assembly of ball joint in front suspension system

Ball joints consist various elements that their responsibilities, geometrical shapes and materials are different. The Figure 2 demonstrates a ball joint depicting its components. The ball joints main components: ball stud provide a mechanical connection between the housing and with castle nut and cotter pin. The ball stud is subject to the highest forces in the ball joint. Housing is the base component designed to accommodate the ball stud and ball bearing. Dust cover is designed for protecting the ball joint from contamination that causes additional wear on the ball bearing and corrosion of the ball stud. One of the main part of the ball joint is a plastic ball bearing due to minimize wear, reduce friction, better vibration damping.


Figure 2. Ball Joint Components 


\section{Materials, Boundary Conditions and Finite Element Analysis}

To achieve the specific objectives this study has its own way of process and application. To determine stress distribution, force reactions and other analysis processes of the ball joint, CAD model is designed at NX Unigraphics 12.0. and imported to the ANSYS Workbench 18.2. Two type of analysis performed at the process which are defined below.

\subsection{Materials}

\begin{tabular}{|c|c|c|c|c|}
\hline \multirow{2}{*}{ Properties } & \multirow{2}{*}{ Physical } & \multicolumn{3}{|c|}{ Material } \\
\cline { 3 - 5 } & & AISI 1040 & AISI 5140 & Delrin 100 \\
\hline \multirow{4}{*}{ Mechanical } & Density (kg/m^3) & $7800-7900$ & $7800-7900$ & 1420 \\
\cline { 2 - 5 } & Poisson's Ratio & $0,27-0,30$ & $0,27-0,30$ & \\
\cline { 2 - 5 } & Young Modulus (MPa) & $2,08 \mathrm{e} 5-2,16 \mathrm{ee} 5$ & $2,08 \mathrm{e} 5-2,16 \mathrm{e} 5$ & 3000 \\
\cline { 2 - 5 } & Tensile Strength (MPa) & 525 & 575 & \\
\cline { 2 - 5 } & Yield Strain (\%) & $24-36$ & $23-35$ & 26 \\
\cline { 2 - 5 } & Yield Strength (MPa) & 355 & 295 & 72 \\
\cline { 2 - 5 } & Compressive Strength (Mpa) & $315-390$ & $260-325$ & 110 \\
\cline { 2 - 5 } & Flexural Modulus (GPa) & $208-216$ & $209-217$ & 2,9 \\
\cline { 2 - 5 } & Hardness (HV) & $143-173$ & $155-190$ & \\
\hline Thermal & Melting Point ( $\left.{ }^{\circ} \mathbf{C}\right)$ & $1430-1510$ & $1430-1510$ & 178 \\
\hline
\end{tabular}

\begin{tabular}{|c|c|c|c|c|c|c|}
\hline \multirow{2}{*}{ Material } & \multicolumn{6}{|c|}{ Chemical Composition } \\
\cline { 2 - 6 } & $\mathbf{C}$ & Mn & P & S & Si & Cr \\
\hline AISI 1040 & $0,37-0,44$ & $0,6-0,9$ & Max. 0,04 & Max. 0,05 & - & - \\
\hline AISI 5140 & $0,38-0,43$ & $0,7-0,9$ & Max. 0,035 & Max. 0,04 & $0,15-0,35$ & $0,7-0,9$ \\
\hline Delrin 100 & \multicolumn{7}{|c|}{ POM (Polyoxymethylene) } \\
\hline
\end{tabular}

Table 1. Material Properties

\subsection{Finite Element Analysis, Study 1 (Axisymmetric Model)}

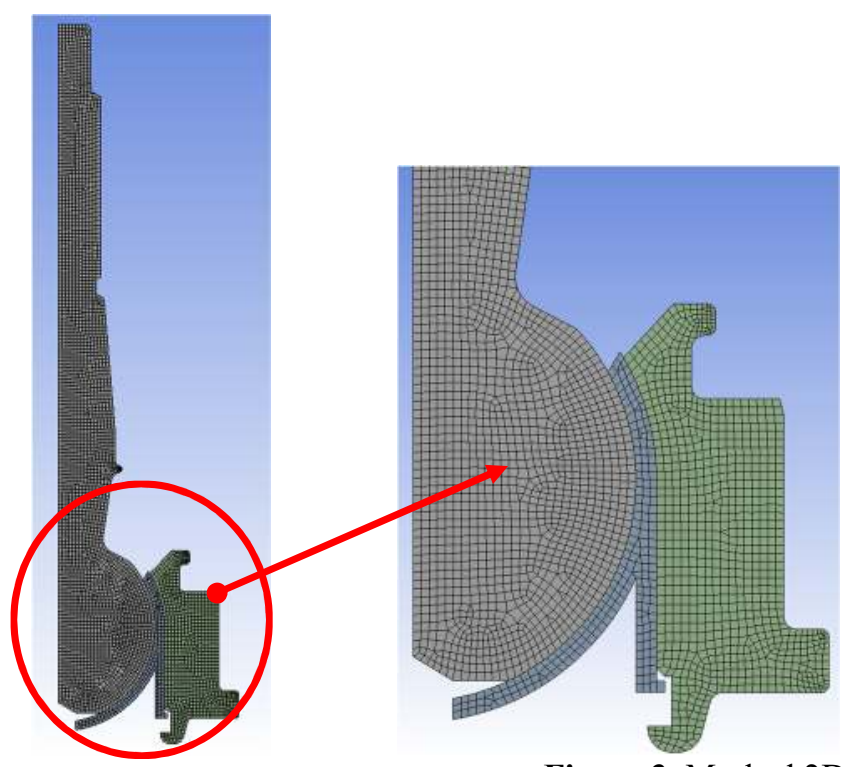

Meshed 2D axisymmetric model of the component consist of 4120 elements and 13077 nodes. Meshed model is as in Figure 3.

Figure 3. Meshed 2D Axisymmetric Model 


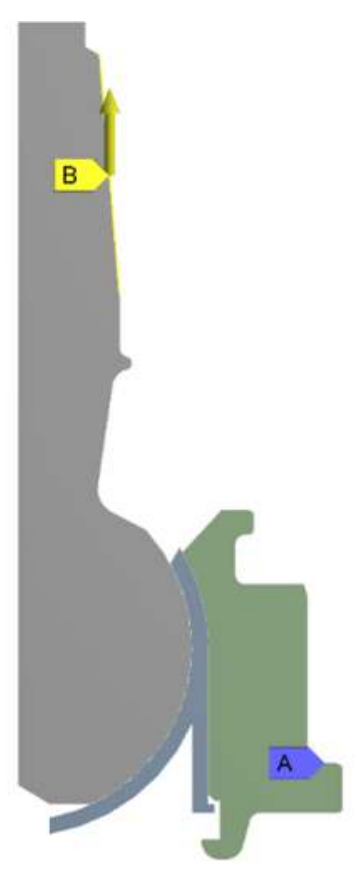

The CAD model is constrained as the body is fixed from point $A$ and the ball stud is forced to pull out from the point $\mathrm{B}$. Boundary conditions are as in Figure 4.

Figure 4. Boundary Conditions of 2D Axisymmetric Model

Stress distribution on the component is shown in the Figure 5 below for axisymmetric model.

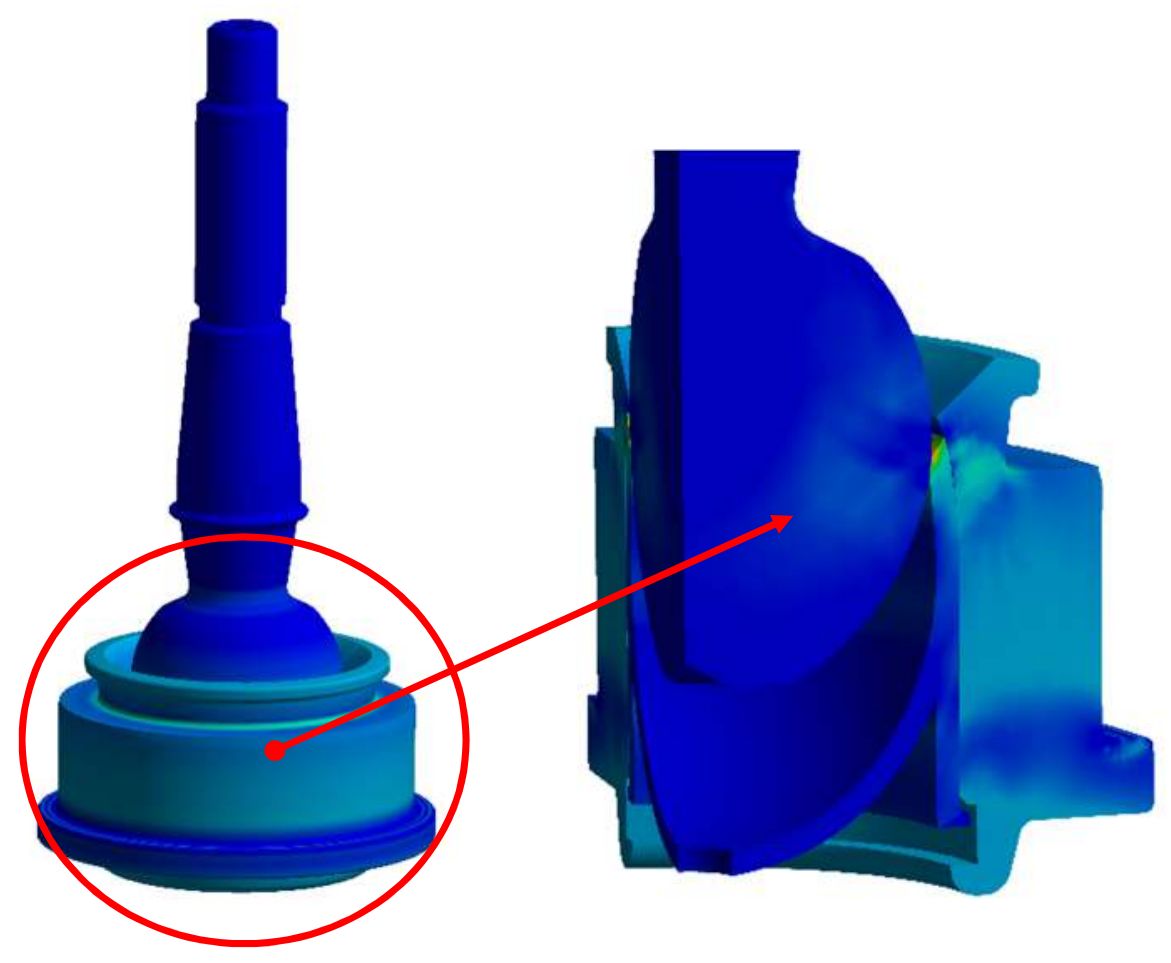

Figure 5. Stress Distribution 2D Axisymmetric Model 


\subsection{Finite Element Analysis, Study 2 (Full Model)}

Meshed 3D full model of the component consist of 35120 elements and 57804 nodes. The CAD model is constrained as the body is fixed from point $\mathrm{A}$ and the ball stud is forced to pull out from the point B. Meshed model and boundary conditions are as in Figure 6 and Figure 7.

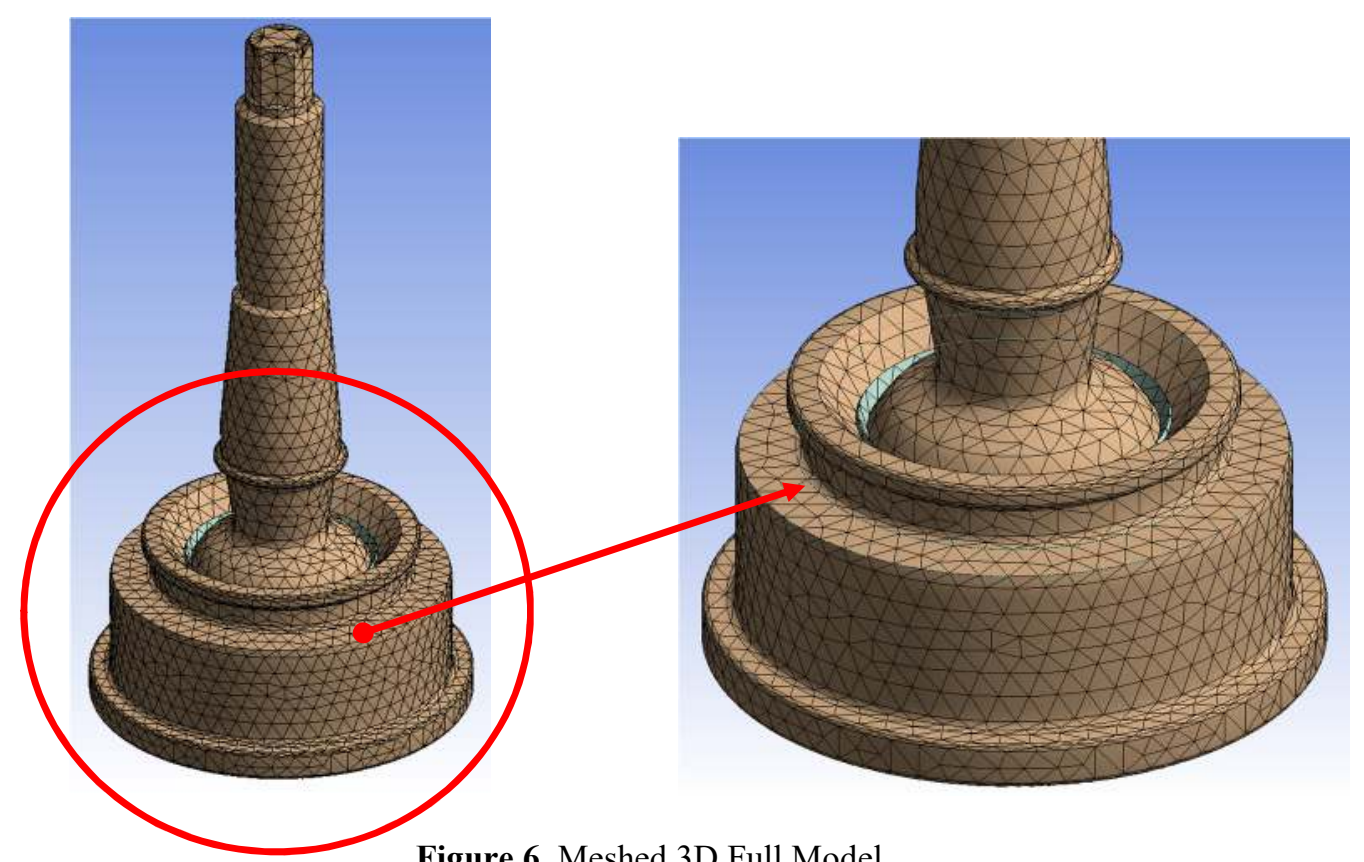

Figure 6. Meshed 3D Full Model

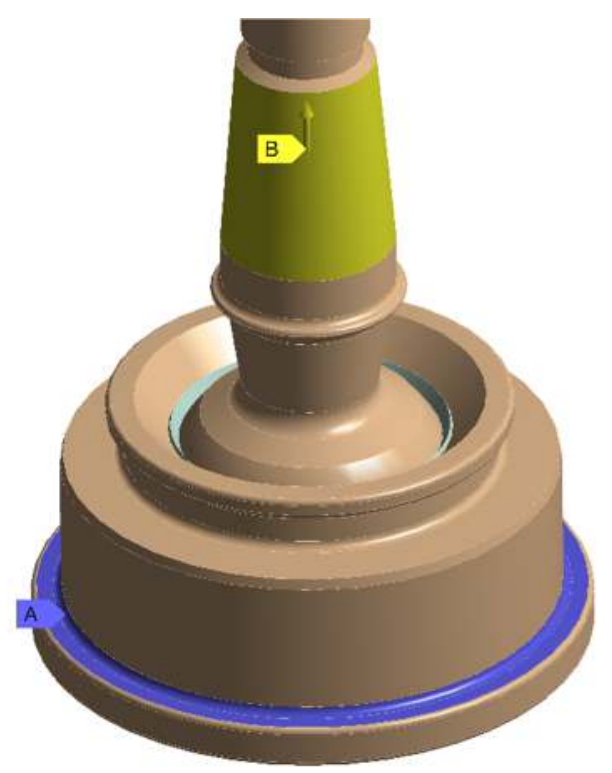

Figure 7. Boundary Conditions of 3D Full Model 
Stress distribution on the component is shown in the Figure 8 below for 3D model.

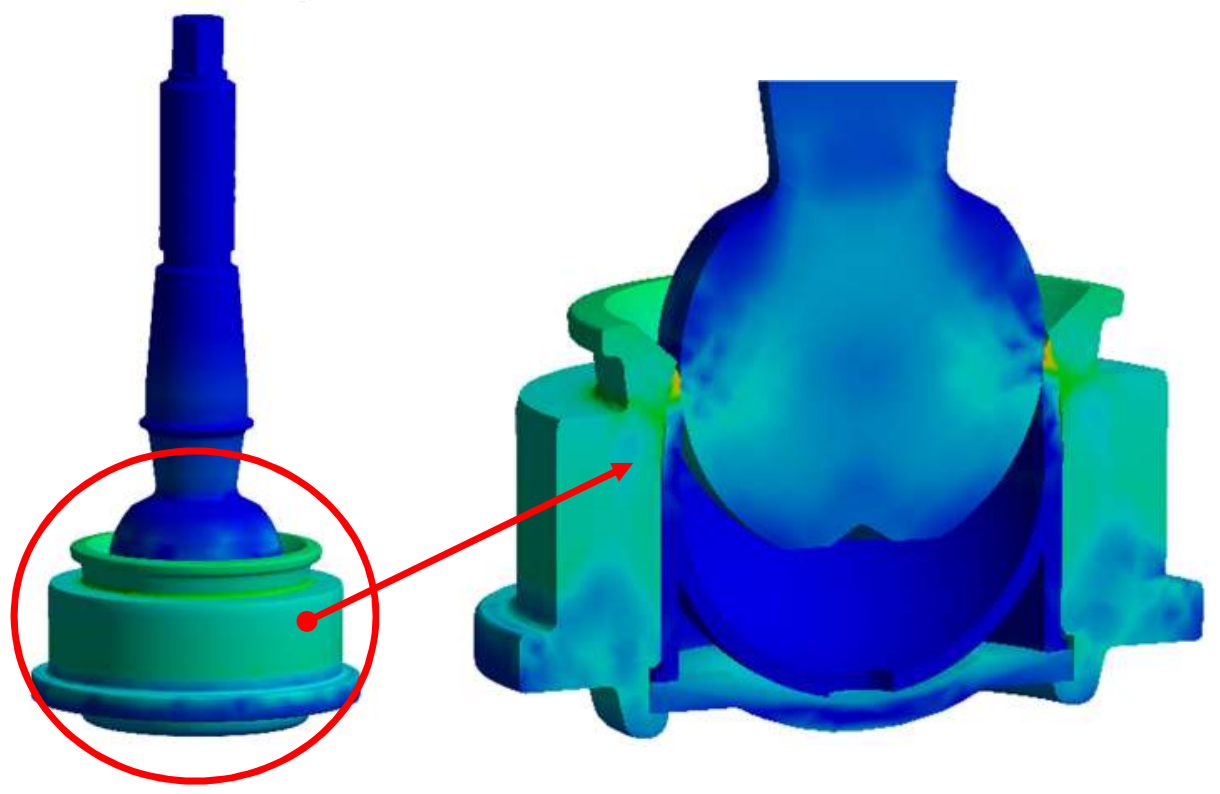

Figure 8. Stress Distribution of 3D Full Model

\section{Experimental Study}

Experimental study is done with the same boundary conditions as applied on the simulation. Three samples used for the experimental study. Average value is taken as reference. Force reaction and so the pull out force is obtained from the test results (Figure 9) and the Force-Strain graph is shown below.

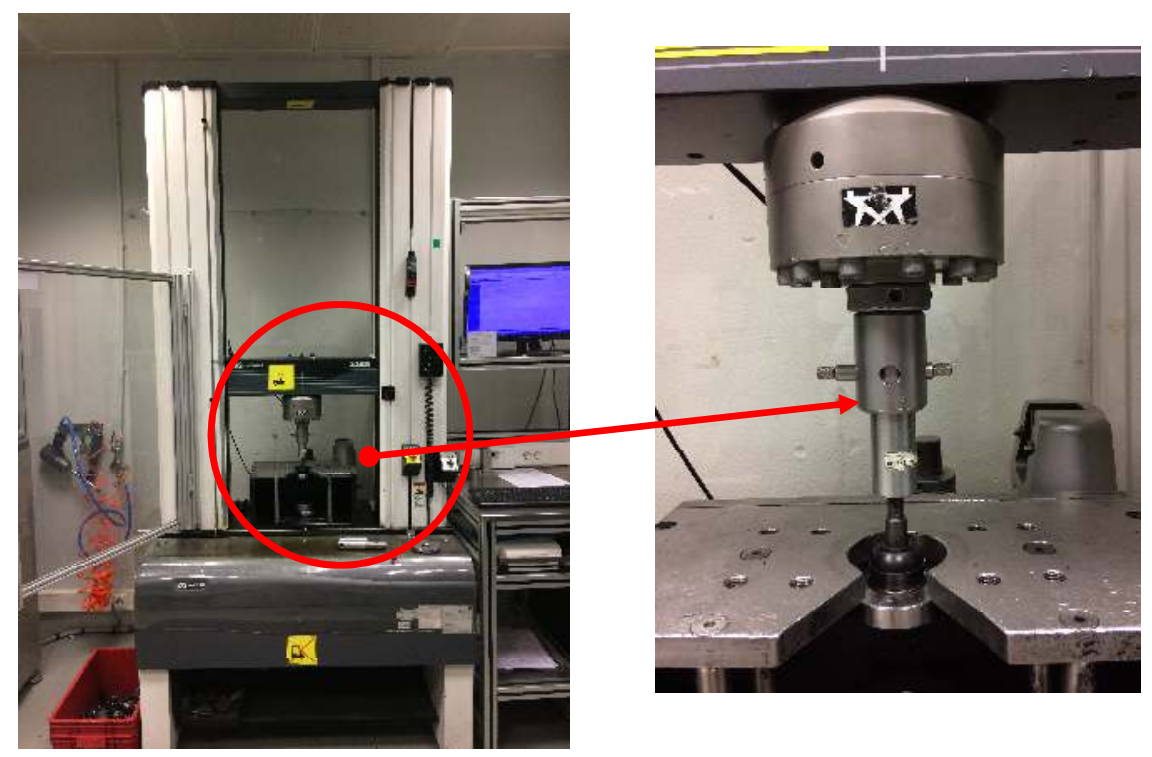

Figure 9. Ball Joint Test Ring 


\section{Conclusions}

It can be seen that stress distribution on both simulations are alike. Another important parameter on this study is the force reactions and the value of the force that will pull the ball stud out. As in Graph. 1 the amount of force is found as $37744 \mathrm{~N}$ average and the results are compared with the simulation results as shown in the Table 2 below.

\begin{tabular}{|c|c|c|c|c|c|}
\hline \multirow{2}{*}{} & \multirow{2}{*}{$\begin{array}{c}\text { Experimental } \\
\text { Test Result }\end{array}$} & \multicolumn{2}{|c|}{ Simulation Result } & \multicolumn{2}{c|}{ Error \% } \\
\cline { 3 - 6 } & $\begin{array}{c}\text { 2D Axisymmetric } \\
\text { Model }\end{array}$ & 3D Full Model & $\begin{array}{c}\text { 2D Axisymmetric } \\
\text { Model }\end{array}$ & 3D Full Model \\
\hline $\begin{array}{c}\text { Pull Out Force } \\
\text { (N) }\end{array}$ & 39347 & 38208 & 38757 & 2,89 & 1,49 \\
\hline
\end{tabular}

Table 2. Comparison of the Results

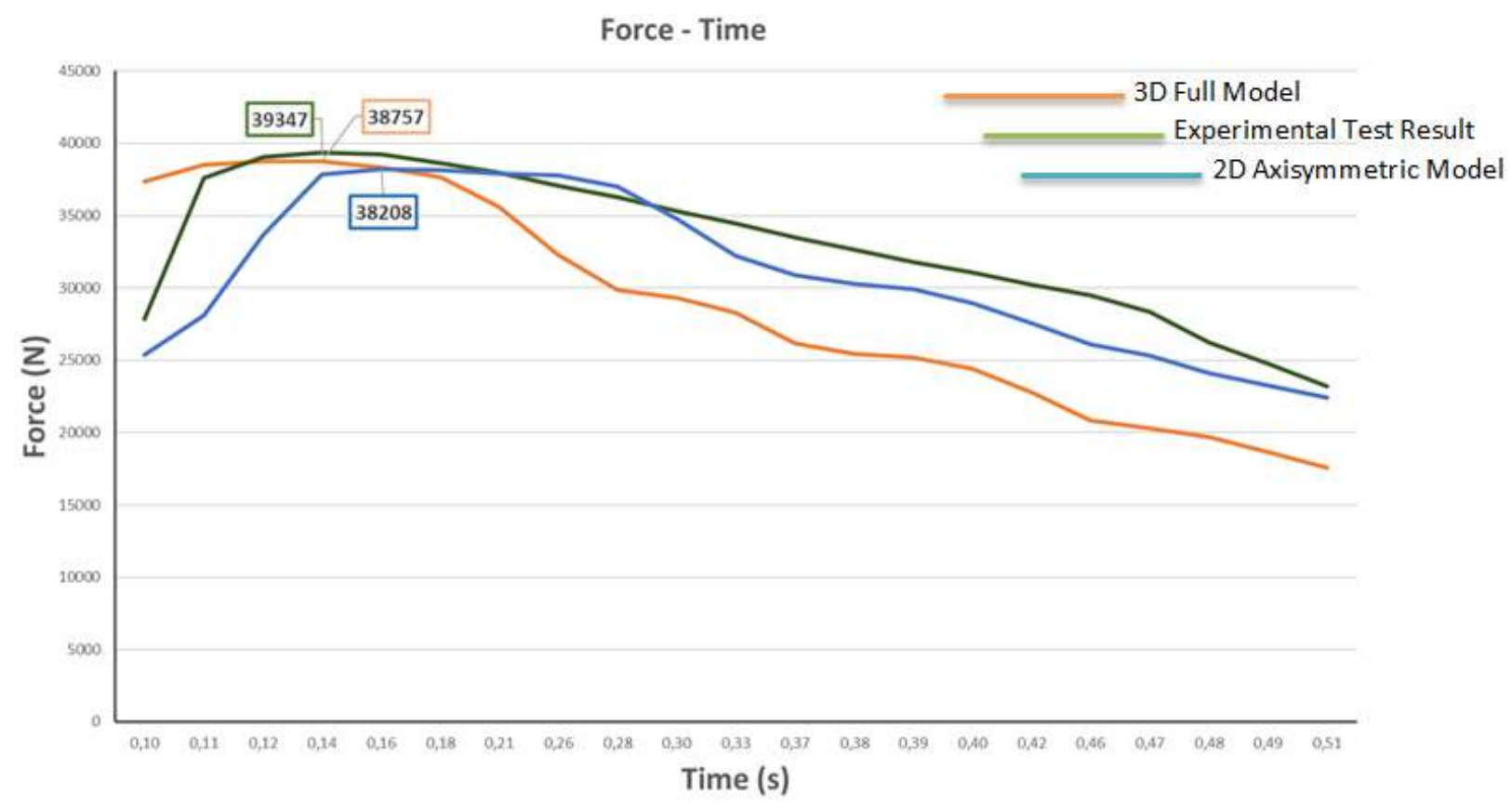

Graph. 1. Pull Out Force Monitor

It is observed that the finite element analysis result and prototype test results are approximately same. The difference between the finite element simulation and the experimental results is $2,89 \%$ for 2D Axisymmetric model and 1,49\% for 3D model. These percentages are considered acceptable for a preventive method, so that the experimental results validated the simulation analysis. This study shows that virtual analysis methods' results leads us how to design robust ball joint before physical prototype phase. 


\section{Acknowledgements}

These study was supported by Teknorot Automotive A.S R\&D Center. We thank our colleagues from R\&D Center who provided insight and expertise of this paper. Also we appreciate to R\&D Director Mr. Murat ARSLANOGLU and R\&D Project Manager Mr. Fatih CAGIRANKAYA for their technical support.

\section{References}

[1] B. Heißing, M. Ersoy (Eds.) Chassis Handbook; Fundamentals, Driving Dynamics, Components, Mechatronics, Perspectives, ISBN 978-3-8348-0994-0

[2] http://dupont.materialdatacenter.com/profiler/main/

[3] Teknorot Automotive R\&D Center Design Guide

[4] https://www.sharcnet.ca/Software/Ansys/17.0/en-us/help/wb_sim/

[5] Herbert Ricardo Rosa M, Marcus Z. Ball Joint Pull Out Simulation using Finite Element Analysis, 2006

[6] Helena Osório F, Artur Pinto de A, Marcus Z, Henrique Nelson S, Sergio Cardoso da S. Suspension ball joint failure analysis based on problem solving process, 2006 